\title{
NEUROMUSCULAR EFFECTS OF SIX LOCAL ANAESTHETICS ON ANAESTHETIZED SUBJECTS
}

\author{
José E. Usubiaga, M.D., and Frank Moya, M.D."
}

THE EFFECT of local anaesthetics on the neuromuscular junction has been extensively studied in the experimental animal. ${ }^{1-5}$ The methods used involved perfusion of isolated nerve-muscle preparations, and the intravenous or intra-arterial injections of the drugs. Most of these techniques have limitations. The isolated nerve-muscle preparation is an in vitro method which eliminates the factor of circulation. Studies based upon intravenous injection are theoretically questionable because all drugs are diluted and some of them metabolized in blood before reaching sites of action in the muscle. Finally, intra-arterial injection does not have any significant drawback. On the basis of these experiments, it has been suggested that local anaesthetics produce a blockade of neuromuscular transmission similar to curare. Animal experimentation, however, cannot be freely extrapolated to man because of species differences in response of the myoneural junction to neuromuscular blockers. ${ }^{6}$ Therefore, to determine whether or not local anaesthetics block neuromuscular transmission in man, the effects of six local anaesthetics injected intra-arterially into anaesthetized patients was studied.

\section{Materials and Methods}

The subjects were 27 adult patients of both sexes, free of any neuromuscular disease, who were scheduled for lower limb or abdominal wall operations. These operative procedures were chosen because of their moderately long duration (two to four hours), minimal blood loss, and slight effect on body temperature.

Premedication consisted of atropine sulfate $(0.4$ to $0.8 \mathrm{mg} . / \mathrm{kg}$.) and sodium pentobarbital (2 to $4 \mathrm{mg}$. $/ \mathrm{kg}$.) given intramuscularly approximately one hour before surgery. General anaesthesia was induced with sodium thiopental ( 1 to 3 $\mathrm{mg} . / \mathrm{kg}$.) and maintained with halothane-nitrous-oxide-oxygen in a semi-closed system. In 13 patients, no muscle relaxants were used, and in the remaining 14 a single dose of succinylcholine chloride $(0.8$ to $1 \mathrm{mg} . / \mathrm{kg}$.) was administered intravenously for tracheal intubation. In these latter subjects a 30-minute interval elapsed before the injection of the experimental drugs. Respiration was spontaneous, assisted, or controlled, as indicated by the need to maintain adequate ventilation. Arterial blood pressure was monitored with an aneroid sphygmomanometer, pulse rate and lead II electrocardiogram with an oscilloscope, and respiratory frequency by observing the movements of the rebreathing bag. All these parameters were measured every five minutes and before and immediately after the injection of local anaesthetic drugs. Finally, in ten patients the skin

Department of Anesthesiology, University of Miami School of Medicine and Jackson Memorial Hospital, Miami, Florida. 
temperature of the experimental and contralateral arms was continuously monitored with a skin probe and a telethermometer.

An upper extremity was positioned in specially designed armboard and the brachial or radial artery cannulated with a no. 23 scalp vein needle. The needle was kept patent by intermittent injections of saline. Heparin was not used because of its anti-curare effect. ${ }^{7}$ Movements of the thumb produced by direct stimulation of the adductor pollicis or by indirect stimulation (via needle electrodes subcutaneously placed in the arm close to the ulnar nerve) were continuously recorded with a Grass displacement transducer (FTC no. 3) and a Grass 5A polygraph recorder. The height of the tracing was adjusted to between 3 and $6 \mathrm{~cm}$. The nerve stimulator was a modification of the "Block-aid monitor,"8 which delivered single supramaximal electrical pulses of .2 milliseconds" duration at a rate of one every two seconds, or a tetanic burst consisting of 40 stimuli per second, maintained up to 5 seconds.

The drugs used were the hydrochlorides of lidocaine (Xylocaine), prilocaine (Citanest), procaine, mepivacaine (Carbocaine), tetracaine (Pontocaine), and dibucaine (Nupercaine). The concentrations of lidocaine, prilocaine, procaine and mepivacaine were $5 \mathrm{mg}$. of the salt per milliliter of saline solution. Concentrations of tetracaine and dibucaine were $2 \mathrm{mg} . / \mathrm{ml}$. All solutions were equilibrated at $\mathrm{pH}$ of 4.5 and injected at room temperature. Doses ranged from 0.1 to $1 \mathrm{mg} . / \mathrm{kg}$. for tetracaine and dibucaine and from 0.1 to $3 \mathrm{mg} . / \mathrm{kg}$. for all the other drugs. Each local anaesthetic was injected as the first drug in at least four subjects, 90 minutes elapsing before subsequent injections. In this way, the minimal dose necessary to produce a 30 to 50 per cent reduction in the single twitch tension was determined. Duration of neuromuscular effect was measured with the tetanus, as the interval elapsing between drug injection and time to recover its control height. The data obtained were subjected to statistical analysis with the Student $t$-test, to determine whether the differences observed were significant.

\section{ResulTs}

During the control period, single stimulation of the ulnar nerve produced a consistent twitching of the fingers, whereas tetanic stimulation showed a potentiated, well sustained contraction during the tetanus and absence of posttetanic potentiation of the twitch.

The most noticeable changes induced by the intra-arterial injection of local anaesthetics were in the coloration of the hand. There was commonly an initial patchy blanching followed by a flushing of the skin. In five out of ten experiments an increase in cutaneous temperature of one to two degrees Fahrenheit was also observed. These transient changes in coloration and temperature were unrelated to the drug used and independent of the degree or duration of the muscle paralysis.

The smallest dose of local anaesthetic did not depress twitch tension. Indeed, on three occasions, a small but noticeable potentiation of the twitch was produced by $0.1 \mathrm{mg} . / \mathrm{kg}$. of lidocaine or carbocaine. With increased doses, however, all 
local anaesthetics first reduced tetanic height and later single twitch tension. The intensity of the effect was a function of the site of injection, the compound used, and the dose employed. The most profound effects were observed following injection into the radial artery. However, muscle paralysis produced via the brachial artery involved most of the fingers, while intra-radial injection depressed mainly the movements of the thumb and index finger. The minimum dose necessary to reduce the twitch tension by 30 to 50 per cent ranged from 0.2 to 0.6 $\mathrm{mg} . / \mathrm{kg}$. of body weight (Table I and Fig. 1). Procaine was the weakest and dibucaine-tetracaine the most potent agent on a weight-for-weight basis. The directly elicited twitch was depressed only after the injection of two to three times the minimum paralysing dose.

TABLE I

Minimal Paralysing Dose and Duration of Muscle Paralysis Induced by Six INTRA-ARTERIALLY INJECTEd LOCAL ANAESTHETICS

\begin{tabular}{|c|c|c|c|c|c|}
\hline & \multirow[b]{2}{*}{ Drug } & \multirow[b]{2}{*}{$\begin{array}{l}\text { Number of } \\
\text { experiments }\end{array}$} & \multirow{2}{*}{$\begin{array}{c}\text { Minimal } \\
\text { paralysing dose } \\
(\mathrm{mg} . / \mathrm{kg} .)\end{array}$} & \multicolumn{2}{|c|}{$\begin{array}{l}\text { Duration of muscle paralysis } \\
\text { (minutes) }\end{array}$} \\
\hline & & & & range & $\begin{array}{l}\text { mean and } \\
\text { standard error }\end{array}$ \\
\hline 1 & Procaine & 16 & 0.6 & $3.10-6.50$ & $4.0 \pm 1.3$ \\
\hline 2 & Lidocaine & 12 & 0.5 & $2.40-8.50$ & $4.1 \pm 1.1$ \\
\hline 3 & Prilocaine & 14 & 0.5 & 1.00-3.20 & $3.4 \pm 0.8$ \\
\hline 4 & Mepivacaine & 11 & 0.4 & $4.00-9.10$ & $5.5 \pm 2.7$ \\
\hline 5 & Tetracaine & 10 & 0.2 & $13.00-47.00$ & $23.1 \pm 7.6$ \\
\hline 6 & Dibucaine & 11 & 0.2 & $19.00-58.00$ & $26.0 \pm 8.2$ \\
\hline
\end{tabular}

In all experiments, the onset of muscle paralysis was rapid, within four seconds after the injection and the peak reached in another two to five seconds. Consistently, single twitch regained its initial tension earlier than tetanic contraction. Recovery was rapid following procaine, prilocaine, lidocaine, and carbocaine. Tetracaine and dibucaine myoneural effects lasted significantly longer than all the other drugs ( see Table I).

Procaine, lidocaine, prilocaine, and mepivacaine had no cumulative effect when the injections were separated by 15 -minute intervals. With shorter intervals, some degree of summation was occasionally observed (Fig. 2). On the other hand, tetracaine and dibucaine had a marked cumulative effect. Furthermore, during the recovery from tetracaine or dibucaine induced paralysis, subparalytic doses of any one of the other local anaesthetics produced a significant depression of the twitch tension (Fig. 3).

No changes in blood pressure, heart rate, or respiratory rate were associated with the injections. In all cases, brachial or radial arteries were fully pulsatile during and after the experiments. Except for one case of haematoma formation, no postoperative subjective or objective changes occurred in the experimental arm. 

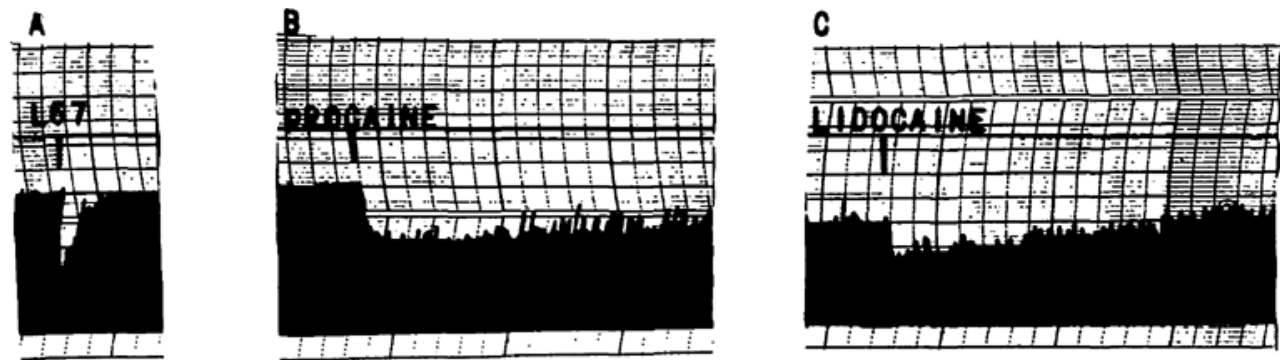

D
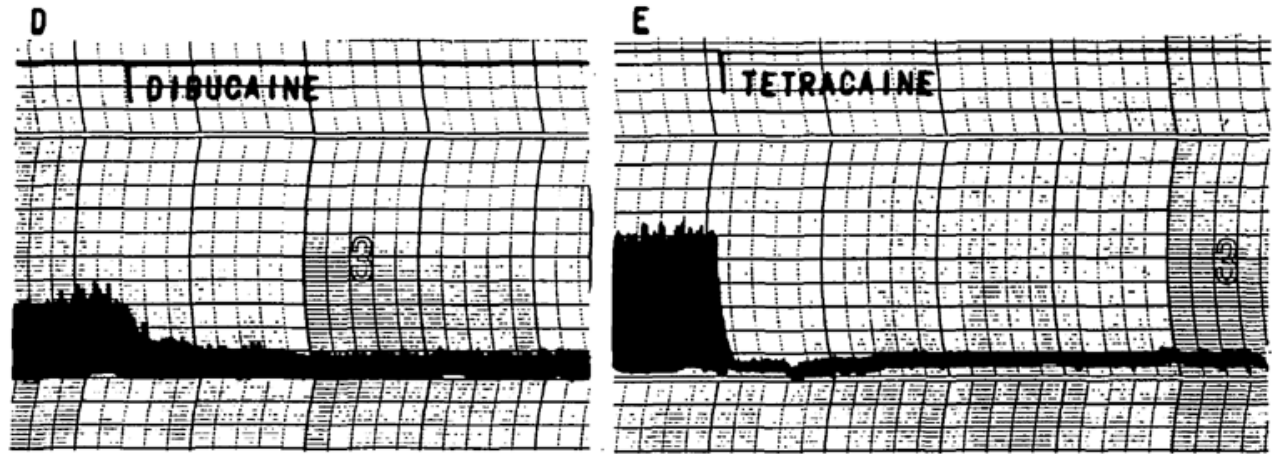

Ficule 1. Experiments $\mathrm{A}, \mathrm{B}$, and $\mathrm{C}$ were performed in the same individual, separated by intervals of 60 minutes. Experiments $\mathrm{D}$ and $\mathrm{E}$ were done in two other subjects. Arrow indicates time of injection of the anaesthetic. The doses injected were: $0.8 \mathrm{mg} . / \mathrm{kg}$. of procaine and prilocaine; $0.7 \mathrm{mg} . / \mathrm{kg}$. of lidocaine; $0.3 \mathrm{mg} . / \mathrm{kg}$. of dibucaine and tetracaine. Note the short duration of the prilccaine induced paralysis compared to that with procaine or lidocaine. The dibucaine and tetracaine induced paralysis exceeded 30 minutes in both cases.

A

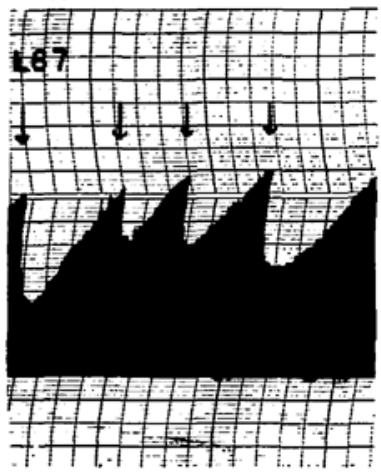

B

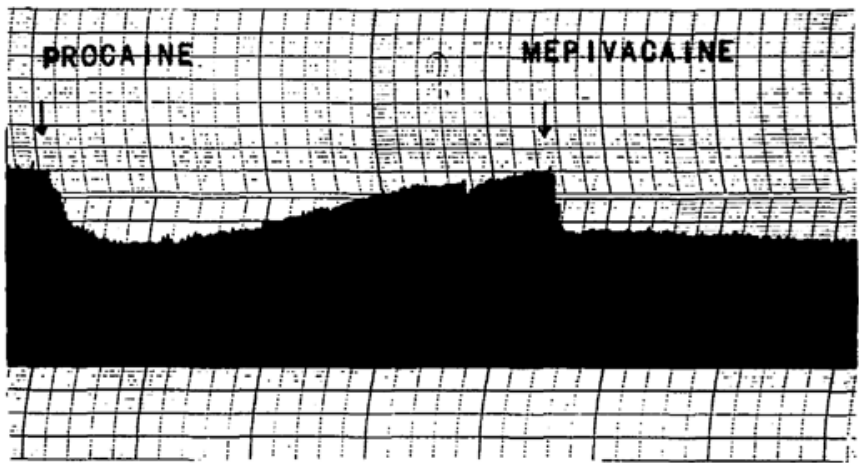

Figure 2. Panel A. Four successive doses of prilocaine injected at intervals of little more than one minute. No cumulative effect observed. Panel $B$. After the recovery of a procaine induced blockade, $0.4 \mathrm{mg} . / \mathrm{kg}$. mepivacaine was injected. Observe marked depression of the twitch tension. 


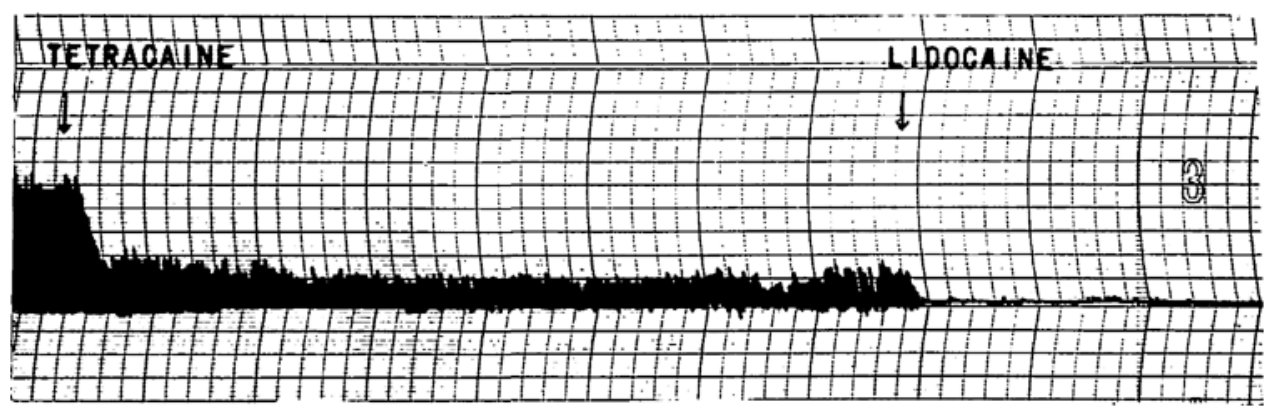

FICUnE 3. At the first arrow, an injection of $0.3 \mathrm{mg} . / \mathrm{kg}$. of tetracaine into the radial artery reduces twitch tension of the adductor pollicis muscle by 60 per cent. Thirteen minutes later, a subparalytic dose of lidocaine $(0.2 \mathrm{mg} . / \mathrm{kg}$.) produces almost 100 per cent block.

\section{Discussion}

The present experiments clearly demonstrate a neuromuscular blockade produced by local anaesthetics. In this regard, local anaesthetics bear a pharmacological resemblance to non-depolarizing muscle relaxants. ${ }^{1}$ In comparison with curare, however, the muscle relaxing effect of local anaesthetics is very mild indeed. To produce neuromuscular blockade, a high drug concentration must reach the myoneural junction. Clinically, this can only occur after intra-arterial administration, or most frequently, following intravenous injection of local anaesthetics distal to an occlusive tourniquet (intravenous regional anaesthesia). In normal individuals, the possibility of neuromuscular depression after systemic injection of local anaesthetics is unlikely.

It has been demonstrated here that tetanic contraction is a more sensitive indicator of local anaesthetic effect than the twitch tension. Local anaesthetic effect on the twitch tension is believed to take place at the postsynaptic membrane. ${ }^{10}$ On the contrary, local anaesthetic effect on the tetanic height could be a manifestation of a drug effect on the motor nerve terminal. Indeed, recent electrophysiological work ${ }^{11}$ has demonstrated that the motor nerve terminal is early affected by local anaesthetics at a time when there is no depression of neuromuscular transmission. This is not surprising, because in peripheral nerves, high frequency potentials are curtailed by local anaesthetics before any effect on the propagation of the single volley takes place. ${ }^{9}$ On that basis, long-lasting depression of tetanic curve could indicate a more prolonged local anaesthetic effect on prejunctional structures. A neural locus of action (prejunctional) is also suggested by the different duration of action of the drugs injected. Differences in duration are not related to local anaesthetic potency, since procaine equals lidocaine, nor are they dependent upon local biotransformation, since a minimal amount of the enzyme pseudocholinesterase is present at the myoneural junction. ${ }^{12}$ More likely, duration of action depends upon two factors: the diffusion rate from the junctional region and the solidity of the bond between the local anaesthetic molecule and the junctional receptor.

Regarding diffusion rate, it is possible that local anaesthetics produce changes in blood flow within the microcirculation, thus modifying the washout rate of 
the drugs. ${ }^{13}$ As for the strength of binding, local anaesthetics can be separated into two groups. ${ }^{14}$ Procaine or lidocaine added to nervous tissue homogenates can be easily recovered by dialysis, whereas tetracaine and dibucaine become so strongly bound that only a small percentage is recovered. On the basis of the present studies, local anaesthetics can also be grouped, according to their myoneural blocking action, into two categories closely resembling those based on nervous tissue binding characteristics. Therefore, it can be reasonably assumed that strength of binding is an important factor in determining the duration of myoneural effects. Furthermore, the cumulative effect of tetracaine and dibucaine suggests that some of the preceding dose is still bound to tissue receptors.

Finally, it should be mentioned that the twitch potentiation occasionally seen following the smallest doses of lidocaine and carbocaine is an unexpected finding. Twitch potentiation produced by small doses of depolarizing skeletal muscle relaxants has been described by Zaimis ${ }^{6}$ and by Riker and Standaert, ${ }^{1 \overline{1}}$ among others. This action, masked by the injection of larger doses, could be produced by stimulation of nerve terminals, depolarization of the postsynaptic membrane, or potentiation of the coupling-contracting mechanism at the muscle fibre site. Its occurrence with non-depolarizing drugs such as local anaesthetics is difficult to explain. The design of the present experiments does not permit us to advance any conclusion in this regard.

\section{Summary AND CONCLUSIONS}

Procaine, lidocaine, mepivacaine, prilocaine, tetracaine, and dibucaine were injected into the brachial or radial artery of surgical patients under halothanenitrous-oxide-oxygen anaesthesia. The adductor pollicis muscle was electrically stimulated either indirectly, via the ulnar nerve, or directly, and the contraction recorded.

All local anaesthetics produced an immediate reduction of the single twitch tetanic muscle tension. The minimum paralysing dose for procaine, lidocaine, prilocaine, and mepivacaine ranged from 0.4 to $0.6 \mathrm{mg} . / \mathrm{kg}$. and for dibucaine and tetracaine from 0.2 to $0.3 \mathrm{mg}$. $/ \mathrm{kg}$. The directly elicited contraction was depressed by doubling or tripling the minimal paralysing dose. Tetracaine and dibucaine had a significantly longer duration of action and a marked cumulative effect. No adverse effects of the experiments were observed.

The results suggest that the duration of muscle paralysis may be related to the strength of binding of local anaesthetics to myoneural junctional receptors. The possibility of a prejunctional site of action on the motor nerve terminal is discussed.

\section{RÉSUMÉ}

On a injecté de la procaïne, de la lidocaïne, de la mépivacaïne, de la prilocaïne, de la tétracaïne et de la dibucaïne dans l'artère radiale d'opérés sous anesthésie à l'halothane-protoxyde-d'azote-oxygène. Le court adducteur du pouce a été stimulé par un courant électrique soit indirectement, par le nerf cubital, ou directement, et on a enregistré la concentration. 
Tous les anesthésiques locaux ont produit une diminution immédiate de la tension musculaire tétanique au moment de la saccade. La dose paralysante minima pour la procaïne, la lidocaïne, la prilocaïne et la mépivacaïne a été de 0.4 à $0.6 \mathrm{mg}$. par kilo, et pour la dibucä̈ne et la tétracaïne de 0.2 à $0.3 \mathrm{mg}$. par kilo. La contraction obtenue directement a été diminuée en doublant ou en triplant la dose paralysante minima. La tétracaine et la débucaïne ont en une durée d'action sensiblement plus longue et un effet cumulatif important. On n'a observé aucun effet nocif à la suite de ces expériences.

Les résultats suggèrent que la durée de la paralysie musculaire peut être en rapport avec la force de liaison entre les anesthésiques locaux et les récepteurs de la plaque myo-neurale. On étudie la possibilité d'une action située avant la jonction myo-neurale sur l'extrémité distale du nerf moteur.

\section{REFERENCES}

1. Harvey, A. M. The Actions of Procaine on Neuromuscular Transmission. Bull. Johns Hopkins Hosp. 65: 334 (1939).

2. MacGrecon, D. F. The Action of Procaine and Cocaine on Mammalian Skeletal Muscle. J. Pharmacol. 66: 360 (1939).

3. Hazard, R.; Corteggiani, E.; \& Renier-Connec, A. Influence de la iodeméthylation sur quelques actions physiologiques d'anesthésiques locaux de formule dérivée de la procaine. Arch. Int. Pharmacodyn. 96: 314 (1954).

4. Geslen, R. \& Tabsuba, M. The Neuromuscular Blocking Action of Local Anaesthetics. J. Pharmacol. 103: 344 (1951).

5. Ellis, C. H.; WNuck, A. L.; DeBeer, E. J.; \& Foldes, F. F. Modifying Actions of Procaine on the Myoneural Blocking Actions of Succinylcholine, Decamethonium, and d-Tubocurarine in Dogs and Cats. Am. J. Physiol. 174: 277 (1953).

6. Zaimis, E. J. Factors Influencing the Action of Neuromuscular Blocking Substances. Lectures on the Scientific Basis of Medicine, N.Y.; John de Graar (1957), p. 208.

7. Cheymol, J.; Bourillet, F.; \& Levassort, C. Action anticurarimimetizue de l'héparine et d'héparionoide de syntèse chez le lapin. J. Physiol. (Paris). 47: 132 (1957).

8. Katz, R. A Nerve Stimulator for the Continuous Monitoring of Muscle-Relaxant action. Anesthesiology. 26: 832 (1965).

9. Shanes, A. M. Electrochemical Aspects of Physiological and Pharmacological Action of Excitable Cells. Pharmacol. Rev. 10: 59 (1958).

10. Funukawa, J. Properties of the Procaine End-Plate Potential. Jap. J. Physiol. 4: 199 (1957).

11. Usumiaca, J. E. Effects of Local Anesthetics on the Motor Nerve Terminals. Fed. Proc. $26: 527$ (1967).

12. Haccvist, G. Cholinesterase and Innervation of Skeletal Muscle. Acta. Phys. Scandinav. 48: 63 (1960).

13. Hurovonien, L.; Konobkin, M.; Sonnenschein, R. R.; \& Whight, D. Depression of Contractile Force of Skeletal Muscle by Intra-arterial Vasodilator Drugs. Circ. Res. 14: 525 (1964).

14. Truant, A. P. \& Takman, B. Differential Physico-chemical and Neuropharmacologic Properties of Local Anesthetic Agents. Anesth. \& Analg. 38: 478 (1959).

15. Riker, W. F., Jr. \& Standaert, F. D. The Action of Facilitatory Drugs and Acetylcholine on Neuromuscular Transmission. Ann. N.Y. Acad. Sc. 134: 163 (1966). 